\title{
Using combined network-based approaches to analyze risk interactions in $\mathrm{RD}$ alliance
}

\author{
Liu, Hui ; Yang, Naiding ; Yang, Zhao ; Zhang, Yanlu ; Li, Ruimeng
}

\begin{abstract}
Previous researches on risks in RD alliance have treated risks independently. They mainly focus on risk identification and the impact of risk on the objectives of alliance. However, most risks are not isolated but interdependent in reality. To address this gap, a combined method that integrates fuzzy DEMATEL and social network analysis is presented to assess and analyze risk interactions in $\mathrm{RD}$ alliance. A case study of a real RD alliance is conducted to identify key risks and their interactions, together with the corresponding mitigation actions. By unveiling risks and their interactions, this method assists professionals to make better decisions regarding risk mitigation, and further helps them to achieve higher performances in RD alliance risk management.
\end{abstract}

DOI: https://doi.org/10.1080/01605682.2020.1796535

Posted at the Zurich Open Repository and Archive, University of Zurich ZORA URL: https://doi.org/10.5167/uzh-193407

Journal Article

Submitted Version

Originally published at:

Liu, Hui; Yang, Naiding; Yang, Zhao; Zhang, Yanlu; Li, Ruimeng (2021). Using combined network-based approaches to analyze risk interactions in RD alliance. Journal of the Operational Research Society, $72(11): 2460-2471$.

DOI: https://doi.org/10.1080/01605682.2020.1796535 


\title{
Using combined network-based approaches to analyze risk interactions in R\&D alliance
}

\author{
Hui Liu ${ }^{a}$ Naiding Yang ${ }^{\mathrm{b}}$ Zhao Yang ${ }^{\mathrm{c}}$ Yanlu Zhang ${ }^{\mathrm{b}} \quad$ Ruimeng $\mathrm{Li}^{\mathrm{d}}$ \\ a School of Business, Central South University, Changsha, China; \\ b School of Management, Northwestern Polytechnical University, Xi'an, China; \\ c URPP Social Networks, University of Zürich, Zürich, Switzerland; \\ $d$ School of Economics and Management, Chongqing University of Posts and \\ Telecommunications, Chongqing, China
}

Corresponding author: Hui Liu, Tel: (86) +13625552319,

Email: huiliu_acdmc@mail.nwpu.edu.cn

Address: Management Building, Lu Shan Nan Lu 932, Yue Lu District, Changsha, Hunan Province, P. R. China, 410086. 


\title{
Using combined network-based approaches to analyze risk interactions in $R \& D$ \\ alliance
}

\begin{abstract}
Previous researches on risks in R\&D alliance have treated risks independently. They mainly focus on risk identification and the impact of risk on the objectives of alliance. However, most risks are not isolated but interdependent in reality. To address this gap, a combined method that integrates fuzzy DEMATEL and social network analysis is presented to assess and analyze risk interactions in R\&D alliance. A case study of a real $\mathrm{R} \& \mathrm{D}$ alliance is conducted to identify key risks and their interactions, together with the corresponding mitigation actions. By unveiling risks and their interactions, this method assists professionals to make better decisions regarding risk mitigation, and further helps them to achieve higher performances in R\&D alliance risk management.
\end{abstract}

Keywords: Risk management; R\&D alliance; Fuzzy theory; DEMATEL; Social network analysis;

\section{Introduction}

With respect to the increasing importance of Research and Development (R\&D) activities, the formation of R\&D collaboration between firms has been an important feature of many industries. It's not surprising that the number of $R \& D$ collaborations has significantly raised over the last decades (Hagedoorn, 2002). Indeed, firms can obtain a certain number of advantages (Gnyawali \& Park, 2009, 2011; Bouncken et al., 2016) from R\&D alliances, such as risk sharing, resource pooling and reputational effects. However, due to the high uncertainty outcomes of R\&D activity, R\&D alliances is still a risky form (Gulati, 1995). For instance, one empirical study claims that R\&D alliances tend to have a high possibility of failure (Dyer \& Singh, 1998), and high levels of risk are considered to be a significant obstacle for the success of $R \& D$ alliances. Within an R\&D alliance, risks are not isolated but usually interrelated. When one risk occurs, one or more other risks may be triggered. This phenomenon, similar to reaction chains, is called risk propagation (Fang et al., 2012), and may lead to the failure of R\&D alliance. Therefore, explicit identification of key risks and analyzing their interactions are meaningful for professionals to make more effective and efficient risk response decisions, achieve higher performance in R\&D alliance risk management, and enhance the success 
rate of $R \& D$ alliance.

Many studies have been conducted to analyze risk interactions in order to support decisionmaking. From a methodological point of view, the current literatures can be divided into two categories: qualitative perspective and quantitative perspective. On the one hand, from the qualitative perspective, some researches (Heinrich et al., 2014; Ward, 1999) point out that cost synergies may lead to increased risk interaction effects in project portfolio. Therefore, assessing and analyzing risk interrelationships is very important when professionals take risk response actions, especially in project portfolios characterized by research and development (Teller et al., 2014). On the other hand, from the quantitative perspective, many risk management methods (Kwan \& Leung, 2011) have been introduced to deal with project risk dependency issues. For instance, based on Design Structure Matrix (DSM) approach, a method (Marle, 2010) has been proposed to group risks in project by considering the complex risk interactions. From a network science point of view, one method (Fang et al., 2012) has been introduced to tackle interrelationship of risks in large engineering projects. Besides, some other quantitative approaches (Aloini et al., 2012a, 2012b; Zhang, 2016; Bhattacharyya et al, 2011) have also been proposed to assess and analyze key risks by considering risk interactions within one project or the project portfolio.

Based on the aforementioned studies, previous researches are mainly focused on risk interactions in the project or the project portfolio. In the area of risk in $\mathrm{R} \& \mathrm{D}$ alliance, previous researches have mainly focused on risk identification and how the risks have impact on the alliance's objectives. In these studies, risks are considered independently. However, it is worth to note that most risks are usually interrelated in reality, and new types of risks, such as trust risk, moral risk and coordination risk, appear due to the collaboration between firms comparing to the independent research and development. Therefore, risks interactions in $R \& D$ alliance is different from their interactions within one project.

To address the above research gaps, in this study, we present a method to deal with the complexity of risks interactions among risks in R\&D alliances. We have employed a combined approach integrating fuzzy Decision Making Trial and Evaluation Laboratory (DEMATEL) and Social Network Analysis (SNA). These two methods can be incorporated harmoniously, because both of them are based on matrices and networks. DEMATEL measures the influence among risks in R\&D 
alliances by taking account into the direct and indirect effect. In the procedure of DEMATEL, available information of criteria is assessed by experts based on their experiences and knowledge, and is often given as crisp values and expressed in linguistic terms due to uncertain and vague. Thus, fuzzy number and triangular fuzzy number are used to represent the linguistic values in the DEMATEL method. Subsequently, we use SNA method to visualize risk network and analyze the risks and their interactions within the whole network.

Using the combined approach of fuzzy DEMATEL and SNA, this study intends to introduce a framework for risk analysis in R\&D networks by taking risk interaction into account. The contributions of this study are twofold. Firstly, there is a paucity of literature on the risk interactions in R\&D alliance, while in reality most risks are not isolated but interrelated. In this context, the risks could be more unpredictable and difficult to manage than first thought. Our approach could analyze risk interaction from a systematic perspective to facilitate the risk response and mitigation actions, which contributes to the literature on risk management. Secondly, the proposed method could provide a lens through which to view the structure of entire risk network in terms of the comprehensive impacts - the risk network contains not only the direct impact but also the indirect impacts among risks by adopting the fuzzy DEMATEL method. Thus, we expect that the outcomes of the analysis can be used to help professionals to identify risks and their interrelationships, and provide useful information to support decision-making of risk mitigation actions.

The rest of this paper is organized as follows. In the next section, risk identification of R\&D alliances is conducted through literature review. The combined approach integrated by fuzzy DEMATEL and SNA is discussed and described in section 3. In section 4, an example of application to a real $R \& D$ alliance is presented to demonstrate the proposed method. Some conclusions and discussions are drawn in section 5.

\section{Risk identification}

To analyze and list major risks followed by classification and sub-categorization of R\&D alliance, the following steps are implemented. Firstly, previous researches on project risk identification and alliance have been reviewed. There is no consensus on risk classification of current literatures, which usually classifies risks into different categories such as technological failure and 
risk of opportunism (Mccutchen et al., 2004), relational risk and performance risk (Das \& Teng, 2001b), environment related risks, market related risks, organization related risks and technology related risks (Kasap et al., 2007), technology risk, sustentation risk, management risk and environment risk (Gu et al., 2009), market risk, economic risk, policy environment risk, ethical risk, time risk, capital risk, and collaboration risk (Zhang \& Yang, 2013, 2018).

There are various classical techniques that can be used to identify risks in R\&D network, such as checklist, brainstorming, fault tree analysis, literature reviews, Delphi method, interviews, etc. In this study two techniques, literature review and interviews, were chosen to identify main risks in R\&D alliance. First, adopting Zhang and Yang's (2013) model, this study accomplishes a border risk list of R\&D alliance according to the various of risks mentioned in the existing literatures. These risks are mainly considered based on the times that appear in the literatures. In this phase, a list of 28 risk has been produced. In the second phase, a panel of six experts, with profound experience in R\&D project management, were interviewed to further add, delete or modify the initial risk list. After an in-depth discussion, laws risk was deleted since it is one risk source of policy. Besides, opportunism risk has been considered as a type of moral risk, thus only moral risk is retained in the final list. Three risks are merged into talent risk, namely staffing volatility, insufficient staffing, and project manager competence. Analogously, frequently evolving customers' demands, coopetition and price changes are all market-related risk. Thus, these risks are replaced by market risk.

19 types of risk of R\&D alliance are finally listed and grouped into two categories according to the sources of risk, namely internal risk and external risk. Internal risk refers to the probability to make the R\&D alliance not achieve the expected objectives. It is caused by various factors arisen from the internal R\&D alliance, and is usually fall under the control of the managers. It includes fourteen types of risk. External risk refers to those factors that may result in the failure to achieve the objectives of R\&D alliance because of external environmental of R\&D alliance, and those risks are beyond the control of managers. Five types of risk are included in this category. These risks and their descriptions are shown in Table 1.

It is important to notice that the aim of Table 1 is to facilitate risk identification for the practitioners and researchers, but it does not cover all the types of risks of R\&D alliance. Risk identification is a continuous process and should be held periodically in order to reveal new risks. 
Therefore we encourage practitioners and researchers to add and eliminate risks according to their own specific scenarios of risk identification at every phase of R\&D.

Table 1. The 19 major risk items in R\&D alliance

\begin{tabular}{|c|c|c|c|c|}
\hline ID & Risk category & Risk characteristic & Remark & Representative References \\
\hline \multirow[t]{2}{*}{1} & cost risk & Budget is exceeded and does not go according to plan, & Internal & (Xu,2008); (Hwang et al., 2016); (Marle et al., 2013); (Qazi \\
\hline & & such as escalation in material price, increase in labor & & et al., 2016); (Feng \& Chen, 2001); (Adler et al., 2016) \\
\hline \multirow[t]{2}{*}{2} & time risk & The member firms may not complete the task on time, & Internal & (Kasap et al., 2007); (Zhang \& Yang, 2013, 2018); (Xu, \\
\hline & & which result in that time schedule is exceeded and does & & 2008); (Wang et al., 2010); (Qazi et al., 2016) \\
\hline \multirow[t]{3}{*}{3} & technology risk & Technology risk refers to possible risks during the stage & Internal & (Mccutchen et al., 2004); (Kasap et al., 2007); (Gu et al., \\
\hline & & of the technical development, such as the complexity of & & 2009); (Das \& Teng, 2001a); (Xu, 2008); (Yin \& Jia, 2013); \\
\hline & & technology, ambiguity in technical methods, etc. & & (Hwang et al., 2016); (Huang, 2010); (Zhang, 2012) \\
\hline \multirow[t]{2}{*}{4} & trust risk & The distrust between member firms influences the & Internal & (Das \& Teng, 2001b); (Liu, 2010); (Xu, 2008); (Yin \& Jia, \\
\hline & & operation of alliance, such as the increasing of cost and & & 2013); (Li \& Liao, 2007) \\
\hline \multirow[t]{4}{*}{5} & talent risk & Talent risk refers to issues associated with $\mathrm{R} \& \mathrm{D}$ & Internal & (Kasap et al., 2007); (Hwang et al., 2016); (Liu et al., 2010); \\
\hline & & personnel that can increase the uncertainty of the & & (Huang, 2010); (Qazi et al., 2016); (Zhang, 2012;) \\
\hline & & alliance's outcome, such as fluctuation of skillful & & \\
\hline & & employees, lack of human resources, and so forth. & & \\
\hline \multirow[t]{3}{*}{6} & moral risk & The risk arises because of the potential opportunistic & Internal & (Mccutchen et al., 2004); (Das \& Teng, 2001a, 2001b); \\
\hline & & behavior of member firms, which is exemplified in & & (Zhang \& Yang, 2018); (Vidal \& Marle, 2008); (Xu, 2008); \\
\hline & & shrinking, cheating, appropriating resources, and so on. & & (Yin \& Jia, 2013); (Sun \& Qi, 2010); (Li \& Liao, 2007) \\
\hline \multirow[t]{3}{*}{7} & knowledge risk & Knowledge risk happens in the process of knowledge & Internal & (Liu, 2010); (Huang, 2010); (Liu, 2013); (Ren \& Huang, \\
\hline & & sharing, communication among members, such as & & 2008); (Su \& Huang, 2011) \\
\hline & & knowledge transfer risk, knowledge leakage risk, etc. & & \\
\hline \multirow[t]{2}{*}{8} & profit risk & The conflicts of the distribution of common profit & Internal & (Xu, 2008); (Yin \& Jia, 2013); (Huang, 2010); (Dan, 2009); \\
\hline & & obtained from the alliance. & & (Qazi et al., 2016); (Zhang, 2012); \\
\hline
\end{tabular}




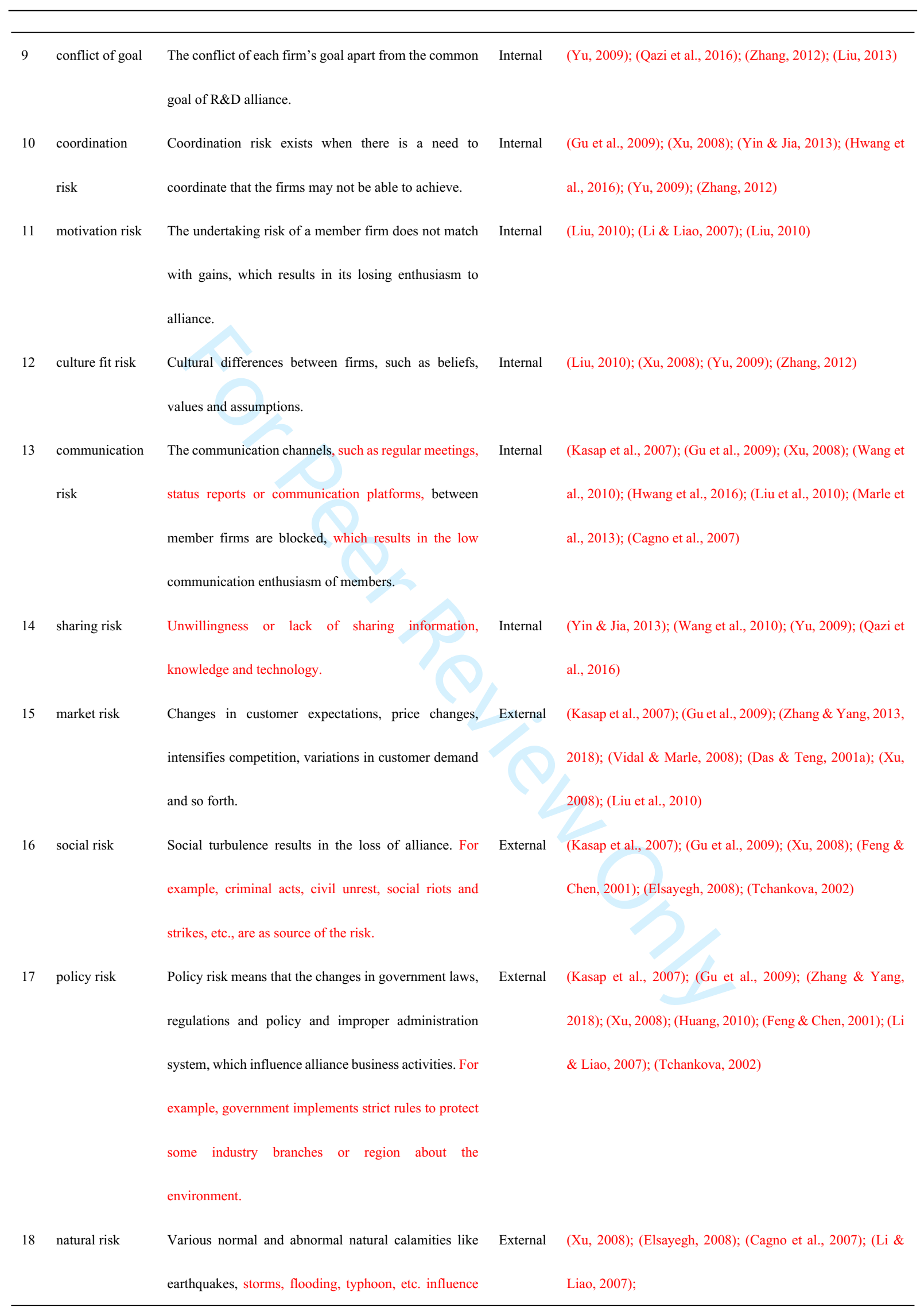


19 financial risk Unexpected changes in interest rates occur and the External (Zhang \& Yang, 2013, 2018); (Xu, 2008); (Feng \& Chen,

fluctuation of exchange rate. $\quad$ 2001); (Cagno et al., 2007)

\section{Methodology}

In order to analyze risk interactions, a combined method integrated by fuzzy DEMATEL and SNA is developed. The procedures of the combined approach are illustrated as follows.

\subsection{Fuzzy DEMATEL method}

DEMATEL (Hsu et al., 2013) is an effective tool on decision-making analysis. It has been used in analyzing the intricate causal relationships among elements. It is proposed by the Battelle Memorial Institute. This method (Ren et al., 2013) can make up for the classical methods such as AHP by assuming that elements are independent. It can therefore be used to analyze the complicated relationships and interactions among elements. Another advantage of this method (Lee et al., 2013; Govindan \& Chaudhuri, 2016) is that it is also suitable for analyzing elements interrelationship with small sample size. DEMATEL can not only calculate the overall strength of receiving and giving impacts among factors, but also measure both direct and indirect influence among the factors. With the aforementioned advantages, we have decided to adopt the DEMATEL tool in our study. Under the setting of DEMATEL, the pair-wise comparison between risk is obtained from the experts based on experience and expertise, which is a qualitative method. The opinion of experts is always expressed in linguistic expressions, thus it is hard to make further analysis because of vague of linguistic evaluations. Hence, in this study, the fuzzy set theory is implemented to transform expert's subjective evaluations into crisp scores.

The procedures of fuzzy DEMATEL are shown below.

Step 1: Develop the pair-wise comparison and design the fuzzy linguistic variables

The interrelationship among risks can be defined as the extent of impact from one risk to the other, which can be acquired from the group of experts. The human assessments are represented as five linguistic terms, which are 'no influence', 'very low influence', 'low influence', 'high influence' and 'very high influence'. According to the linguistic variable, the linguistic evaluations from experts 
Table 2. The fuzzy linguistic scale

\begin{tabular}{cc}
\hline Linguistic terms & Triangular fuzzy numbers \\
\hline No influence (No) & $(0,0,0.25)$ \\
Very low influence (VL) & $(0,0.25,0.50)$ \\
Low influence (L) & $(0.25,0.50,0.75)$ \\
High influence (H) & $(0.50,0.75,1.00)$ \\
Very high influence (VH) & $(0.75,1.00,1.00)$ \\
\hline
\end{tabular}

Step 2: Transform triangular fuzzy numbers into the initial direct-relation Matrix ' $Z$ '

In this step, Converting Fuzzy data into Crisp Scores (CFCS) (Opricovic \& Tzeng, 2003) have be implemented as defuzzification method aggregation to obtain a crisp value. Based on this method, the maximum and minimum of fuzzy number range is determined, and the scrip score can be calculated in the form of average weighted scores through the membership function. Following the step 1, those fuzzy numbers are defuzzified and aggregated as a crisp value which is the $z_{i j}$. Thus, the initial direct-relation matrix $Z=\left[z_{i j}\right]_{n \times n}$ ( $\mathrm{n}$ is the number of risk) can be obtained by the CFCS method. The details are described as follows.

(1) Normalization:

$$
\begin{aligned}
& x r_{i j}^{k}=\left(r_{i j}^{k}-\min l_{i j}^{k}\right) / \Delta_{\min }^{\max } \\
& x m_{i j}^{k}=\left(m_{i j}^{k}-\min l_{i j}^{k}\right) / \Delta_{\min }^{\max } \\
& x r_{i j}^{k}=\left(l_{i j}^{k}-\min l_{i j}^{k}\right) / \Delta_{\min }^{\max }
\end{aligned}
$$

where $\Delta_{\min }^{\max }=\max r_{i j}^{k}-\min l_{i j}^{k}$

(2) Calculate right (rs) and left (ls) normalized values:

$$
x r s_{i j}^{k}=x r_{i j}^{k} /\left(1+x r_{i j}^{k}-x m_{i j}^{k}\right)
$$




$$
x l s_{i j}^{k}=x m_{i j}^{k} /\left(1+x m_{i j}^{k}-x l_{i j}^{k}\right)
$$

(3) Calculate total normalized crisp values:

$$
x_{i j}^{k}=\left[x l s_{i j}^{k}\left(1-x l s_{i j}^{k}\right)+x r s_{i j}^{k}\right] /\left[1-x l s_{i j}^{k}+x r s_{i j}^{k}\right]
$$

(4) Calculate crisp values:

$$
Z_{i j}^{k}=\min l_{i j}^{k}+x_{i j}^{k} \Delta_{\min }^{\max }
$$

(5) Integrate crisp values:

$$
Z_{i j}=1 / H\left(Z_{i j}^{1}+Z_{i j}^{2}+\mathrm{K}+Z_{i j}^{H}\right)
$$

Step 3: Determine the normalized direct-relation matrix " $D$ ".

In this step, the normalized direct-relation matrix $\mathrm{D}$ can be calculated from the direct-relation matrix $Z$ by Eqs. (9) and (10).

$$
\begin{aligned}
& D=S \times Z \\
& S=\frac{1}{\max _{1 \leq i \leq n} \sum_{j=1}^{n} z_{i j}}
\end{aligned}
$$

Step 4: Construct the total relation matrix " $M$ "

Following the step 3, the total relation matrix $M$ is calculated from the normalized matrix $D$ with the assistance of Eq. (11).

$$
M=D(I-D)^{-1}
$$

where $I$ stands for the identity matrix.

Step 5: Set up a threshold value.

The total relation matrix might provide too much information of risk interactions, which may go against the professional decision-makings. In this case, filtering out some negligible effects among risks to obtain a total relation matrix by calculating a threshold value is very necessary. In this paper, the threshold value is obtained by computing the mean of the total relation matrix $M$.

\subsection{Decipherment of risk network by Social Network Analysis (SNA)}

Once risks (nodes) and risk interrelationship (links) are identified, a risk network can be obtained by applying fuzzy DEMATEL method. The risk network, which can be described by a directed and 
weighted graph $G(N, K)$, contains $\mathrm{N}$ nodes (the identified risks) and $\mathrm{K}$ weighted arrows (risk interrelationship). In the following, we use two groups of SNA indicators to describe the structural configurations of risk relations: network measure and node/link measure.

\subsubsection{Network measure}

In order to get further understanding of risk network, network density is used to get insights on the global characteristics of risk network.

Network density (Fang et al., 2012), noted as Density $(G)$, indicates the degree of connectivity of members, and is defined as the ratio between the existing links and the number of possible links in a network:

$$
\operatorname{Density}(G)=\frac{K}{N(N-1)}=\left(\sum_{R_{i}, R_{j} \in G} R S M_{R_{i}, R_{j}}\right) / N(N-1)
$$

Where $R S M$ is the adjacency matrix of risk network calculated by the fuzzy DEMATEL method. $R_{i}$ and $R_{j}$ are the elements in the risk network. $N$ is the number of identified risks, which equals to the number of nodes in the risk network. The value of network density is between 0 and 1 . When the network density is high, risks are more interrelated with each other in the network.

\subsubsection{Node/link measures}

In this part, two node/link measures are used to indicate the role of individual risk by taking immediate or mediate interrelationship in the risk network into account. These measures are node centrality, and node/link betweenness centrality.

(1) node degree centrality

In the directed risk graph, we use in-degree centrality and out-degree centrality to denote the immediate connectivity of a risk. In-degree centrality means the degree of incoming relations that the node impacted by its neighbor, while out-degree centrality denotes the degree of out-coming that the node impact to its neighbors. Node degree centrality are represented as Eq. (14) and Eq. (15).

$$
\begin{aligned}
& \text { InDegree }_{R_{i}}=\sum_{R_{j} \in G} \operatorname{RSM}_{R_{j} R_{i}} \\
& \text { OutDegree }_{R_{i}}=\sum_{R_{j} \in G} \operatorname{RSM}_{R_{i} R_{j}}
\end{aligned}
$$


A high value of in-degree centrality means that the risk is highly impacted by other risks. In contrast, the value of out-degree centrality denotes the degrees that other risks are impacted by the risk.

Based on the degree centrality, nodes can be categorized into 5 types (Wasserman \& Faust, 1994): (1) 'isolate' node, this type node has no links in risk network; (2) 'transmitter' node has only out-degree and no in-degree; (3) 'receiver' node, which has only in-degree and no out-degree; (4) 'carrier' node has only one out link and one in link; (5) 'ordinary' node, which are nodes that do not belong to the above-mentioned categories.

(2) node/link betweenness centrality

Node (link) betweenness centrality (Parise, 2007) is based on the idea that a given node (a link) lies between many other nodes. A higher betweenness centrality means that the node or the link has a high impact on the whole risk network. The calculation of betweenness centrality is based on the shortest path, and it can be calculated by using Dijkstra algorithm proposed by Dijkstra. According to the betweenness centrality in the social network, node and link betweenness centrality can be calculated by the Eq. (16) and Eq. (17).

$$
\begin{gathered}
\text { Betweenness }\left(R_{i}\right)=\sum_{R_{i}, R_{j}, R_{k} \in G, R_{i} \neq R_{j} \neq R_{k}} \delta_{R_{j}, R_{k}}\left(R_{i}\right) \\
\text { Betweenness }\left(R_{i} \rightarrow R_{j}\right)=\sum_{R_{q}, R_{i}, R_{j}, R_{p} \in G, R_{q} \neq R_{i} \neq R_{j} \neq R_{p}} \delta_{R_{q}, R_{p}}\left(R_{i}, R_{j}\right)
\end{gathered}
$$

Where $\delta_{R_{j}, R_{k}}\left(R_{i}\right)$ is the total number of shortest paths that passes through node $R_{i}$. Similarly, $\delta_{R_{q}, R_{p}}\left(R_{i}, R_{j}\right)$ stands for the number of shortest paths in the network through the link between node $R_{i}$ and node $R_{j}$

\subsection{Identification of mitigation actions}

The results derived from the combined method are used to identify the importance of risks together with the corresponding mitigation actions. In short, managers should pay more attention to the nodes (risks) with higher out-degree and betweenness centrality; and to the links (risk interactions) with higher betweenness centrality.

In order to validate the effectiveness of mitigation actions, two phases can be implemented: Immediate test: At this point, the identified key risks and their interactions will be removed from 
the risk network, then we compare the value of network measure with the initial value of network measure before taking the mitigation actions. From the theoretical perspective, if the value of network measure decreases sharply, the mitigation actions are effective.

Periodic test: Considering the change of R\&D environment during the R\&D lifecycle, the status of the risk network should be monitored and periodic reviews conducted. According to the different stages of R\&D, new risks can be identified, and the existing risks can also be delated from the current risk list. Then, the information used in the first step of fuzzy DEMATEL should be modified. As a result, the risk network could be updated and the indicators should be calculated correspondingly. Thereby, the risk mitigation actions will be implemented and the effectiveness of the executed actions can be evaluated.

The general steps of the combined method include: (1) identifying risks in R\&D alliance; (2) constructing an over-all impact risk network through fuzzy DEMATEL; (3) analyzing the risk network using the SNA; (4) presenting the analysis results; (5) testing the proposed risk mitigation actions. The general process of the proposed model in this research is illustrated in Figure. 1. We have also indicated the relationships between the general steps of the combined method and the process of classical risk management. Besides, the outcomes of each step are described in Figure. 1. 
Methods

Steps

Risk management

process

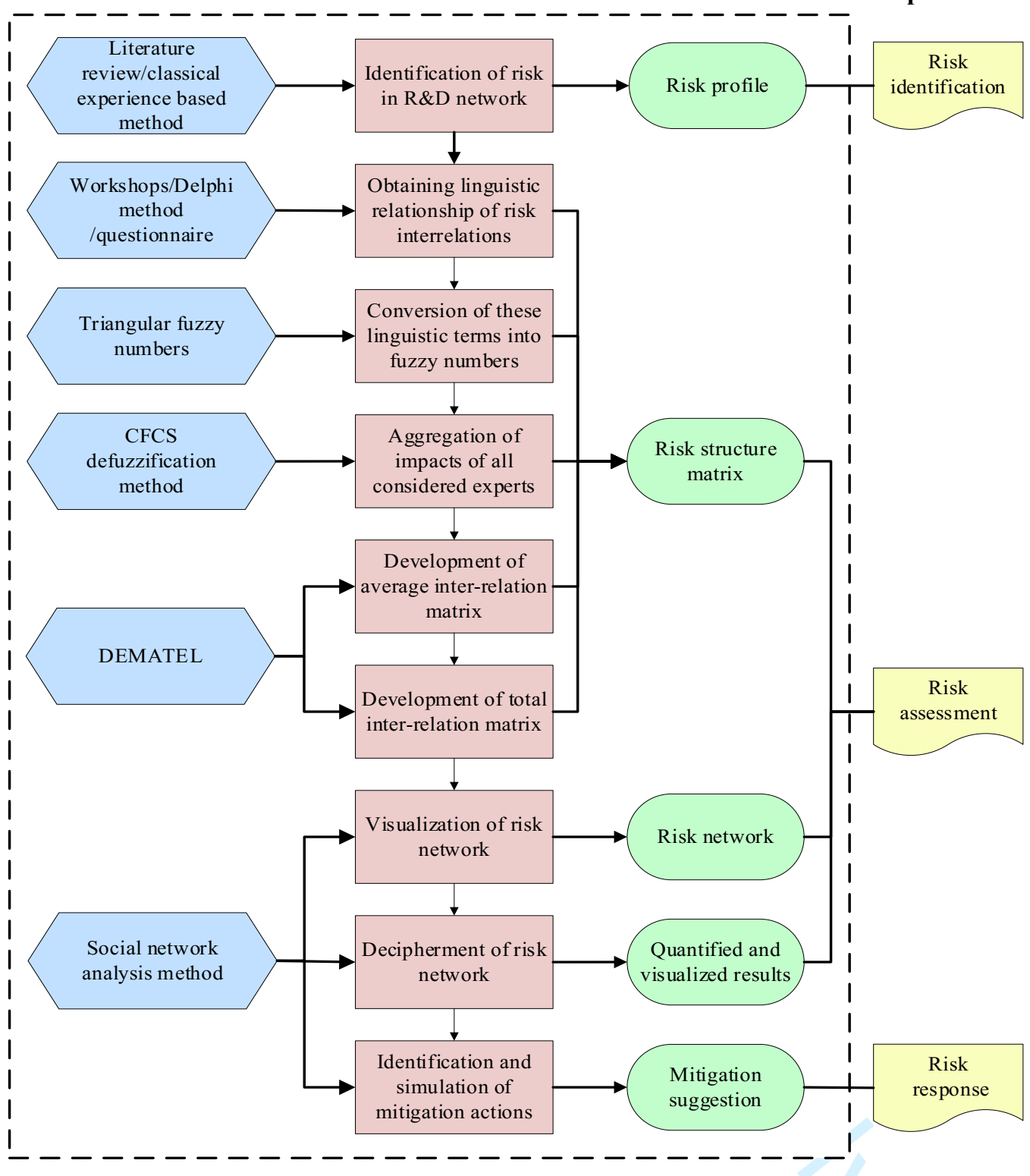

Figure. 1 Framework of the combined risk management method

\section{An application of R\&D alliance risk management procedure using the proposed method}

With the help of the master of business of administration (MBA) teaching center in a leading university in China, a real $\mathrm{R} \& \mathrm{D}$ alliance is employed to illustrate the analysis procedures of the risk interactions. The R\&D alliance is formed among four firms in Xi'an (the capital city of Shanxi province, China), and it lasts for two years with the aim of a new software development. Through indepth interviews with the managers of these four firms, we have built up an expert group. The panel 
of experts is consisted of six experts, including 2 firm managers and 4 critical R\&D talents. The detailed procedures are as follow.

\subsection{Building up the risk network}

Firstly, a questionnaire is designed for data collection. It consists of two parts. For easy understanding and response, the first part outlines the explanations of each risk. Nineteen risks identified shown in Table 1 are adopted to evaluate the risk interrelationships in the R\&D alliance. The second part is designed with the aim to evaluate the influence among risks by a pair-wise comparison using fuzzy linguistic scale in Table 2. Then, the evaluation data about interrelationships among all 19 risks was collected from the six experts by conducting the questionnaire. With the assistance of Eq. (3) to Eq. (8) (CFCS defuzzification method), the linguistic assessments from experts are transformed into crisp values, which represent the impacts of every risk on the others. Based on this, the initial direct-relation matrix is calculated (see Table 3 for details). Next, the totalrelation matrix $\mathrm{T}$ is obtained by using Eq. (11) (see Table 4 for details). Then, in order to filter out the negligible effects, a threshold value is set up by calculating the average of elements of matrix $\mathrm{T}$. And only the effect of risk interactions greater than the threshold value are shown in the risk network. Finally, the risk network G $(19,170)$ is shown in Figure. 2, which is visualized using Pajek. The node shapes indicate the risk categories.

Table 3. The initial direct-relation matrix

\begin{tabular}{cccccccccccccccccccc}
\hline & $\mathrm{R}_{1}$ & $\mathrm{R}_{2}$ & $\mathrm{R}_{3}$ & $\mathrm{R}_{4}$ & $\mathrm{R}_{5}$ & $\mathrm{R}_{6}$ & $\mathrm{R}_{7}$ & $\mathrm{R}_{8}$ & $\mathrm{R}_{9}$ & $\mathrm{R}_{10}$ & $\mathrm{R}_{11}$ & $\mathrm{R}_{12}$ & $\mathrm{R}_{13}$ & $\mathrm{R}_{14}$ & $\mathrm{R}_{15}$ & $\mathrm{R}_{16}$ & $\mathrm{R}_{17}$ & $\mathrm{R}_{18}$ & $\mathrm{R}_{19}$ \\
\hline $\mathrm{R}_{1}$ & 0.04 & 0.50 & 0.38 & 0.15 & 0.15 & 0.04 & 0.25 & 0.75 & 0.25 & 0.25 & 0.50 & 0.04 & 0.15 & 0.15 & 0.38 & 0.15 & 0.15 & 0.15 & 0.26 \\
$\mathrm{R}_{12}$ & 0.85 & 0.04 & 0.38 & 0.25 & 0.15 & 0.15 & 0.15 & 0.63 & 0.25 & 0.38 & 0.25 & 0.04 & 0.04 & 0.15 & 0.38 & 0.04 & 0.04 & 0.15 & 0.26 \\
$\mathrm{R}_{13}$ & 0.63 & 0.62 & 0.04 & 0.26 & 0.25 & 0.26 & 0.50 & 0.15 & 0.25 & 0.15 & 0.38 & 0.15 & 0.15 & 0.25 & 0.50 & 0.15 & 0.15 & 0.04 & 0.04 \\
$\mathrm{R}_{14}$ & 0.50 & 0.38 & 0.15 & 0.04 & 0.25 & 0.63 & 0.50 & 0.38 & 0.74 & 0.63 & 0.38 & 0.15 & 0.63 & 0.74 & 0.04 & 0.15 & 0.04 & 0.04 & 0.15 \\
$\mathrm{R}_{15}$ & 0.63 & 0.62 & 0.50 & 0.38 & 0.04 & 0.38 & 0.62 & 0.50 & 0.25 & 0.15 & 0.50 & 0.15 & 0.25 & 0.38 & 0.15 & 0.15 & 0.15 & 0.15 & 0.04 \\
$\mathrm{R}_{16}$ & 0.38 & 0.63 & 0.25 & 0.62 & 0.25 & 0.04 & 0.63 & 0.63 & 0.38 & 0.62 & 0.75 & 0.25 & 0.50 & 0.50 & 0.15 & 0.15 & 0.15 & 0.15 & 0.15 \\
$\mathrm{R}_{17}$ & 0.63 & 0.74 & 0.63 & 0.50 & 0.38 & 0.50 & 0.04 & 0.85 & 0.38 & 0.38 & 0.25 & 0.25 & 0.63 & 0.50 & 0.15 & 0.26 & 0.15 & 0.15 & 0.04 \\
$\mathrm{R}_{18}$ & 0.50 & 0.25 & 0.25 & 0.50 & 0.38 & 0.38 & 0.25 & 0.04 & 0.38 & 0.38 & 0.50 & 0.25 & 0.50 & 0.50 & 0.38 & 0.15 & 0.15 & 0.15 & 0.26
\end{tabular}


$\begin{array}{llllllllllllllllllll}\mathrm{R}_{19} & 0.38 & 0.38 & 0.25 & 0.62 & 0.38 & 0.50 & 0.38 & 0.62 & 0.04 & 0.50 & 0.50 & 0.25 & 0.63 & 0.62 & 0.26 & 0.15 & 0.15 & 0.15 & 0.04\end{array}$

$\begin{array}{llllllllllllllllllll}\mathrm{R}_{10} & 0.63 & 0.63 & 0.50 & 0.63 & 0.25 & 0.38 & 0.38 & 0.63 & 0.38 & 0.04 & 0.63 & 0.15 & 0.50 & 0.50 & 0.15 & 0.15 & 0.04 & 0.04 & 0.04\end{array}$

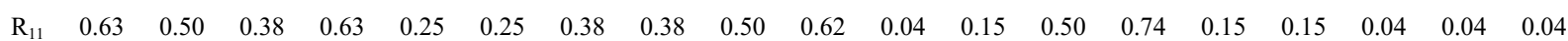

$\begin{array}{llllllllllllllllllll}\mathrm{R}_{12} & 0.62 & 0.38 & 0.25 & 0.50 & 0.15 & 0.38 & 0.25 & 0.50 & 0.50 & 0.50 & 0.50 & 0.04 & 0.38 & 0.50 & 0.15 & 0.04 & 0.15 & 0.04 & 0.04\end{array}$

$\begin{array}{llllllllllllllllllll}\mathrm{R}_{13} & 0.50 & 0.50 & 0.38 & 0.50 & 0.15 & 0.38 & 0.25 & 0.38 & 0.38 & 0.62 & 0.38 & 0.15 & 0.15 & 0.50 & 0.15 & 0.04 & 0.15 & 0.04 & 0.04\end{array}$

$\begin{array}{llllllllllllllllllll}\mathrm{R}_{14} & 0.38 & 0.50 & 0.38 & 0.38 & 0.25 & 0.25 & 0.25 & 0.38 & 0.50 & 0.63 & 0.63 & 0.15 & 0.38 & 0.15 & 0.04 & 0.04 & 0.15 & 0.04 & 0.04\end{array}$

$\begin{array}{llllllllllllllllllll}\mathrm{R}_{15} & 0.74 & 0.63 & 0.50 & 0.38 & 0.15 & 0.25 & 0.50 & 0.63 & 0.25 & 0.38 & 0.38 & 0.04 & 0.25 & 0.15 & 0.04 & 0.38 & 0.38 & 0.04 & 0.26\end{array}$

$\begin{array}{llllllllllllllllllll}\mathrm{R}_{16} & 0.38 & 0.50 & 0.50 & 0.25 & 0.25 & 0.25 & 0.26 & 0.38 & 0.50 & 0.50 & 0.15 & 0.38 & 0.38 & 0.38 & 0.50 & 0.04 & 0.38 & 0.15 & 0.50\end{array}$

$\begin{array}{llllllllllllllllllll}\mathrm{R}_{17} & 0.63 & 0.38 & 0.50 & 0.15 & 0.15 & 0.04 & 0.15 & 0.50 & 0.38 & 0.25 & 0.38 & 0.04 & 0.15 & 0.25 & 0.38 & 0.15 & 0.04 & 0.04 & 0.38\end{array}$

$\begin{array}{llllllllllllllllllll}\mathrm{R}_{18} & 0.38 & 0.26 & 0.50 & 0.25 & 0.15 & 0.15 & 0.15 & 0.15 & 0.04 & 0.38 & 0.15 & 0.04 & 0.25 & 0.15 & 0.38 & 0.25 & 0.50 & 0.04 & 0.38\end{array}$

$\begin{array}{llllllllllllllllllll}\mathrm{R}_{19} & 0.50 & 0.38 & 0.25 & 0.25 & 0.15 & 0.15 & 0.15 & 0.38 & 0.15 & 0.15 & 0.38 & 0.15 & 0.25 & 0.25 & 0.50 & 0.38 & 0.63 & 0.15 & 0.04\end{array}$

Table 4. The total-relation matrix

\begin{tabular}{|c|c|c|c|c|c|c|c|c|c|c|c|c|c|c|c|c|c|c|c|}
\hline & $\mathrm{R}_{1}$ & $\mathrm{R}_{2}$ & $\mathrm{R}_{3}$ & $\mathrm{R}_{4}$ & $\mathrm{R}_{5}$ & $\mathrm{R}_{6}$ & $\mathrm{R}_{7}$ & $\mathrm{R}_{8}$ & $\mathrm{R}_{9}$ & $\mathrm{R}_{10}$ & $\mathrm{R}_{11}$ & $\mathrm{R}_{12}$ & $\mathrm{R}_{13}$ & $\mathrm{R}_{14}$ & $\mathrm{R}_{15}$ & $\mathrm{R}_{16}$ & $\mathrm{R}_{17}$ & $\mathrm{R}_{18}$ & $\mathrm{R}_{19}$ \\
\hline $\mathrm{R}_{1}$ & 0.23 & 0.26 & 0.20 & 0.19 & 0.12 & 0.13 & 0.17 & 0.30 & 0.18 & 0.20 & 0.24 & 0.07 & 0.17 & 0.19 & 0.16 & 0.08 & 0.08 & 0.06 & 0.10 \\
\hline $\mathrm{R}_{2}$ & 0.32 & 0.19 & 0.19 & 0.19 & 0.11 & 0.14 & 0.15 & 0.28 & 0.17 & 0.21 & 0.20 & 0.07 & 0.15 & 0.18 & 0.15 & 0.07 & 0.07 & 0.06 & 0.10 \\
\hline $\mathrm{R}_{3}$ & 0.31 & 0.29 & 0.17 & 0.21 & 0.13 & 0.16 & 0.21 & 0.24 & 0.19 & 0.20 & 0.23 & 0.08 & 0.18 & 0.21 & 0.17 & 0.08 & 0.09 & 0.05 & 0.07 \\
\hline $\mathrm{R}_{4}$ & 0.37 & 0.33 & 0.23 & 0.25 & 0.17 & 0.26 & 0.26 & 0.34 & 0.31 & 0.33 & 0.31 & 0.11 & 0.31 & 0.34 & 0.15 & 0.10 & 0.09 & 0.06 & 0.10 \\
\hline $\mathrm{R}_{5}$ & 0.36 & 0.33 & 0.26 & 0.26 & 0.13 & 0.21 & 0.25 & 0.32 & 0.22 & 0.24 & 0.29 & 0.10 & 0.23 & 0.27 & 0.15 & 0.10 & 0.10 & 0.07 & 0.08 \\
\hline $\mathrm{R}_{6}$ & 0.39 & 0.38 & 0.26 & 0.34 & 0.18 & 0.20 & 0.29 & 0.39 & 0.29 & 0.35 & 0.37 & 0.13 & 0.31 & 0.33 & 0.17 & 0.11 & 0.11 & 0.08 & 0.11 \\
\hline $\mathrm{R}_{7}$ & 0.42 & 0.40 & 0.31 & 0.32 & 0.20 & 0.26 & 0.22 & 0.42 & 0.28 & 0.32 & 0.31 & 0.13 & 0.32 & 0.33 & 0.18 & 0.13 & 0.12 & 0.08 & 0.10 \\
\hline $\mathrm{R}_{8}$ & 0.35 & 0.29 & 0.23 & 0.29 & 0.18 & 0.21 & 0.22 & 0.27 & 0.25 & 0.28 & 0.30 & 0.12 & 0.27 & 0.29 & 0.18 & 0.10 & 0.10 & 0.07 & 0.11 \\
\hline $\mathrm{R}_{9}$ & 0.37 & 0.34 & 0.25 & 0.33 & 0.19 & 0.25 & 0.25 & 0.38 & 0.23 & 0.32 & 0.33 & 0.13 & 0.31 & 0.34 & 0.18 & 0.11 & 0.11 & 0.08 & 0.09 \\
\hline $\mathrm{R}_{10}$ & 0.39 & 0.36 & 0.27 & 0.32 & 0.17 & 0.23 & 0.25 & 0.37 & 0.27 & 0.25 & 0.33 & 0.11 & 0.28 & 0.31 & 0.16 & 0.10 & 0.09 & 0.06 & 0.09 \\
\hline $\mathrm{R}_{11}$ & 0.38 & 0.33 & 0.25 & 0.31 & 0.17 & 0.21 & 0.24 & 0.33 & 0.27 & 0.32 & 0.25 & 0.11 & 0.28 & 0.33 & 0.16 & 0.10 & 0.09 & 0.06 & 0.09 \\
\hline $\mathrm{R}_{12}$ & 0.36 & 0.30 & 0.22 & 0.28 & 0.14 & 0.21 & 0.21 & 0.32 & 0.26 & 0.29 & 0.29 & 0.09 & 0.25 & 0.29 & 0.15 & 0.08 & 0.10 & 0.06 & 0.08 \\
\hline $\mathrm{R}_{13}$ & 0.33 & 0.30 & 0.23 & 0.27 & 0.14 & 0.20 & 0.20 & 0.30 & 0.23 & 0.29 & 0.27 & 0.10 & 0.21 & 0.27 & 0.14 & 0.08 & 0.09 & 0.05 & 0.08 \\
\hline $\mathrm{R}_{14}$ & 0.31 & 0.30 & 0.23 & 0.25 & 0.15 & 0.18 & 0.20 & 0.29 & 0.25 & 0.29 & 0.29 & 0.09 & 0.24 & 0.23 & 0.13 & 0.08 & 0.09 & 0.05 & 0.07 \\
\hline $\mathrm{R}_{15}$ & 0.39 & 0.34 & 0.27 & 0.27 & 0.15 & 0.20 & 0.25 & 0.35 & 0.23 & 0.27 & 0.28 & 0.09 & 0.23 & 0.24 & 0.15 & 0.13 & 0.14 & 0.06 & 0.12 \\
\hline
\end{tabular}

URL: https://mc.manuscriptcentral.com/ors-jors 


\subsection{Results of network analysis}

After obtaining the risk network, the network level metric can be calculated, namely network density. The value of network density equals to 0.4971 , which shows that the risk network of this R\&D alliance is relatively dense. From the network measures, the risk interactions are very intricate when taking the propagation effects into account.

Five risks with a large value of in-degree and out-degree were selected to display in Table 5. R1 (cost risk) has the highest value of in-degree, followed by R2 (schedule risk), R8 (profit risk), R11 (motivation risk) and R14 (sharing information risk). These risks are easily impacted by the other risks but have less impact on the other risks in the whole network. This can be regarded as 
accumulation risks. From the sequence of risk in-degree, we can see that the cost risk and schedule risk are the top two risks impacted by the other risks. Indeed, the occurrence of other types of risks could lead to the schedule delay of the R\&D activity, and then increase the cost. According to the values of out-degree, the five top risks are R6 (moral risk), R7 (knowledge risk), R9 (conflict of goal), R4 (trust risk) and R15 (market risk). As the results show that moral risk has the highest out-degree in all risks, we note that moral risk (R6) is the most important coming resource to other risks. Some studies (Das \& Teng, 2001b; Zhang \& Yang, 2018; Sun et al., 2010) also have manifested that moral risk is the most common risk existing in the alliance. Besides, four risks are only existing in $R \& D$ collaboration compared to the independent $\mathrm{R} \& \mathrm{D}$ activity. These risks can be also called relational risk. Our example shows that the relational risks are the most important risks to be avoided in R\&D alliance. Therefore, the R\&D alliance should take some measures to prevent the occurrence of these risks. Besides, most of risks in the R\&D alliance are ordinary nodes with in links and out links. This indicates that the occurrence of one risk may trigger other potential risks, which show that risk management is much more complex when considering risk interactions. Table 6 shows the transmitters in the risk network. These are risks that do not have direct incoming impact. We observe that among these 6 risks, four are external risks. This indicates that external risk has significant influences on other risks, but is minimal impacted by the other risks.

The top five nodes with highest betweenness centrality are displayed in Table 7, together with the top five arcs. These risks act as hubs to connect some pairs of risks, such as R8 (profit risk) and R11 (motivation risk). And most of these important arcs are related to the five top risks. Based on Table 7 and Table 5, the four risks including R8 (profit risk), R1 1 (motivation risk), R10 (coordination risk) and R3 (technology risk) play important roles in the risk network, although they do not have high direct impacts on the other risks.

Table 5. The top five risks according to the in-degree and out-degree

\begin{tabular}{lllll}
\hline Rank & Risk ID & In-degree & Risk ID & Out-degree \\
\hline 1 & R1 & 6.27872 & R6 & 3.70951 \\
2 & R2 & 5.63614 & R7 & 3.70067 \\
3 & R8 & 5.70247 & R9 & 3.46907
\end{tabular}


3.40312

3.37432

Table 6. Transmitters in the risk network

\begin{tabular}{lll}
\hline Risk ID & Risk & Remark \\
\hline $\mathrm{R}_{5}$ & Talent risk & Internal \\
$\mathrm{R}_{12}$ & Culture fit risk & Internal \\
$\mathrm{R}_{16}$ & Social risk & External \\
$\mathrm{R}_{17}$ & Policy risk & External \\
$\mathrm{R}_{18}$ & Natural risk & External \\
$\mathrm{R}_{19}$ & Financial risk & External \\
\hline
\end{tabular}

Table 7. The top risks and risk interactions according to the betweenness centrality

\begin{tabular}{lllll}
\hline Rank & Risk ID & Betweenness & Arc ID & Betweenness \\
& & centrality & & centrality \\
\hline 1 & R8 & 19.333 & $\mathrm{R} 2 \rightarrow \mathrm{R} 10$ & 6.367 \\
2 & $\mathrm{R} 11$ & 10.167 & $\mathrm{R} 18 \rightarrow \mathrm{R} 8$ & 6.333 \\
3 & $\mathrm{R} 10$ & 4.900 & $\mathrm{R} 1 \rightarrow \mathrm{R} 8$ & 4.834 \\
4 & $\mathrm{R} 4$ & 3.500 & $\mathrm{R} 2 \rightarrow \mathrm{R} 8$ & 4.833 \\
5 & $\mathrm{R} 3$ & 3.167 & $\mathrm{R} 8 \rightarrow \mathrm{R} 6$ & 4.817 \\
\hline
\end{tabular}

\subsection{Risk mitigation actions and testing}

The results obtained by the application of the combined method are useful for R\&D network risk management. These proposed indicators could help the manager to identify key risks by considering the complicated risk propagation effects. On the basis of the results obtained in the previous section, the corresponding risk mitigation actions are proposed together with testing of the effects of mitigation actions.

Nine critical risks are developed by combining the results in Table 5 and Table 7 . These critical risks are confirmed by node out-degree centrality or node betweenness centrality. Generally, these risks either directly affect the other risks or severely increase the complexity of risk interactions. 
Thus, those kinds of risks should be allocated with more resources and be mitigated with high priority. Eight of the identified critical risks are in the category of internal, and only one is external risk. We note that the external risks are difficult to be eliminated by firms in advance. Firms usually carry out the mitigation actions by risk perception through the risk forecasting system. Therefore, in order to mitigate risk, firms should mainly focus on the eight critical risks remarked as "internal risk".

Moreover, the identified risk interactions with high betweenness centrality value are shown in Table 6. Ideally, removing some of these links will mitigate the propagation effects of the interrelations. The propagation phenomenon can be mitigated through the efficient allocation of resources on these critical risks, which can reduce the exposure of the overall risk. As an example, a combined mitigation action was proposed and tested. It includes four steps: (1) avoid R4 (trust risk); (2) avoid R8 (profit risk); (3) avoid R10 (coordination risk); and (4) avoid R11 (motivation risk). Due to the fact that the links with high betweenness centrality are all related to the nodes with high betweenness centrality, when removing the nodes mentioned-above, the corresponding links are cut off together. In other words, the application of these actions means to remove the nodes (risks) from the risk network. These four risks are all relational risk, and belonging to the internal risk. In order to prevent these risks, a better relation of cooperation should be established at the beginning of the R\&D alliance. By applying these mitigation actions, the initial risk network of the R\&D alliance is shrunk into a graph composed of 15 nodes connected by 77 links, which is shown in Figure. 3. By comparing Figure. 3 with the original risk network in Figure. 2, we can see that the risk interactions have been significantly decreased. After undertaking the above-mentioned mitigation actions, the values of the network measures have been changed. For instance, the value of graph density has been decreased from 0.497 to 0.366 by $26.36 \%$. The new top four risks with the highest betweenness centrality are shown in Table 8, together with the top four risk interactions with the highest betweenness centrality. Comparing to Table 7, the rank of risks and their interactions are different. This indicates that the conduction of the mitigation actions can significantly decrease of the complexity of the risk network. Due to the limitations, only the immediate test is implemented in the case study. It is noteworthy that the risk network should be reviewed and monitored periodically in the future, in order to identify new risks and update the analysis results. 


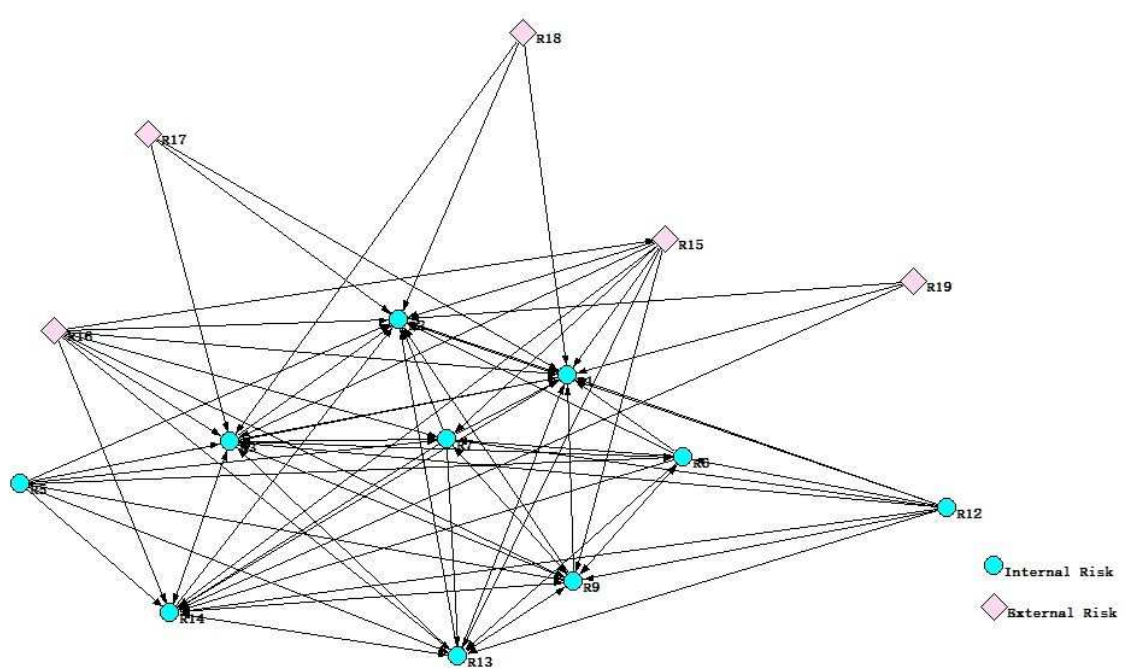

Figure. 3 Structure of the risk network after taking mitigation actions

Table 8. The top four risks and interactions according to the betweenness centrality after taking mitigation actions

\begin{tabular}{lllll}
\hline Rank & Risk ID & Betweenness & Arc ID & Betweenness \\
& & centrality & & centrality \\
\hline 1 & R3 & 11.5 & R3 $\rightarrow$ R7 & 10.5 \\
2 & R14 & 8.0 & R14 $\rightarrow$ R9 & 6.5 \\
4 & R7 & 7.0 & R3 $\rightarrow$ R14 & 6.0 \\
\hline
\end{tabular}

\section{Discussions and conclusions}

This study presents a combined method integrated by fuzzy DEMATEL method and SNA method to analyze the complexity of risk interactions in R\&D alliance. Firstly, by applying the Fuzzy DEMATEL, the proposed method integrates not only the direct but also the indirect impacts among risks in R\&D alliance. Secondly, by using Social Network Analysis (SNA) we unveil the characteristics of risks in term of the comprehensive impacts. The proposed model provides a series of indicators together with a structured procedure for $\mathrm{R} \& \mathrm{D}$ alliance management to identify key risks and their interactions. An application of the proposed method on a real R\&D alliance is presented with the involvement of managers and experts. Based on our analysis, risk mitigation actions have 
been proposed and applied on the risk network. The analytic results can provide useful information for managers to understand risk interactions and facilitate the decision-making process. Furthermore, the effectiveness of risk mitigation actions can be also simulated and tested by the proposed method.

A case study was conducted to analysis risk interaction in R\&D alliance. Several important findings and corresponding managerial implications from the case study include: (1) Relational risk, such as moral risk, knowledge risk, trust risk, etc. are the important coming resource to other risks. Thus, in order to avoid other risks arising at later stages, more attentions should be payed to these risks at the beginning of the alliance. For instance, goodwill trust together with complete contract are more likely to be effective for this kind of risks. (2) From the result of the mitigation test, managers could mitigate the risk propagation phenomena by allocating more resources to those risks or risk interactions with high betweenness centrality value. (3) Due to the great uncertainty of R\&D, the entire risk management of $R \& D$ alliance is an iterative process. Once the $R \& D$ alliance forms, the proposed approach should be proceeded through each step concurrently to monitor and control the risks. Meanwhile, risk identification, the first step of risk management, should also be held continuously for revealing new risks.

Overall, in this work, a combined method has been used to study conventional negative risks. There are some limitations in our research: Firstly, some risks may also bring a positive effect to R\&D alliance. Therefore, positive risks and their interactions should be taken into account in risk network in the future work. Secondly, the mitigation actions are only proposed without considering their cost and benefit. Therefore, in order to assist the manager to optimize the resource under constraints, an analytical framework for cost and benefit is needed. Finally, the proposed method should be applied on more case studies to consolidate the findings presented in this paper.

\section{Acknowledgements}

This work is supported by the National Natural Science Foundation of China (71471146, 71871182,71501158), soft science research project in Shannxi province (2017KRM058), the Fundamental Research Funds for Central Universities (3102018JCC013), and the URPP Social Networks at University of Zurich.

\section{Disclosure statement}

No potential conflict of interest was reported by the authors. 


\section{References}

Adler, T. R., Pittz, T. G., Meredith, J. R. (2016). An analysis of risk sharing in strategic R\&D and new product development projects. International Journal of Project Management, 34(6), 914922. doi : 10.1016/j.ijproman.2016.04.003

Aloini, D., Dulmin, R., Mininno, V. (2012a). Modelling and assessing ERP project risks: a Petri Net approach. European Journal of Operational Research, 220(2), 484-495. doi: 10.1016/j.ejor.2012.01.062

Aloini, D., Dulmin, R., Mininno, V. (2012b). Risk assessment in ERP projects. Information Systems, 37(3), 183-199. doi: 10.1016/j.is.2011.10.001

Bhattacharyya, R., Kumar, P., Kar, S. (2011). Fuzzy R\&D portfolio selection of interdependent projects. Computers \& Mathematics with Applications, 62(10), 3857-3870. doi: 10.1016/j.camwa.2011.09.036

Bouncken, R. B, Plüschke, B. D, Pesch, R., Kraus S. (2016). Entrepreneurial orientation in vertical alliances: joint product innovation and learning from allies. Review of Managerial Science, 10(2), 381-409. doi 10.1007/s11846-014-0150-8

Cagno, E., Caron, F., Mancini, M. (2007). A multi-dimensional analysis of major risks in complex projects. Risk Management, 9(1), 1-18. doi:10.1057/palgrave.rm.8250014

Das, T. K., Teng, B. (2001a). A risk perception model of alliance structuring. Journal of International Management, 7(1), 1-29. doi: 10.1016/S1075-4253(00)00037-5

Das, T. K., Teng B. (2001b). Trust, control, and risk in strategic alliances: An integrated framework. Organization studies, 22(2), 251-283. doi: 10.1177/0170840601222004

Dyer, J. H, Singh, H. (1998). The relational view: Cooperative strategy and sources of interorganizational competitive advantage. Academy of management review, 23(4), 660-679. doi: 10.5465/amr.1998.1255632

Elsayegh, S. M. (2008). Risk assessment and allocation in the UAE construction industry. International Journal of Project Management, 26(4), 431-438. doi: 10.1016/j.ijproman.2007.07.004

Fang, C., Marle, F., Zio, E., Bocquet, J. (2012). Network theory-based analysis of risk interactions in large engineering projects. Reliability Engineering \& System Safety, 106, 1-10. doi: 


\subsection{6/j.ress.2012.04.005}

Feng, W. D., Chen, J. (2001). Study on risk analysis and monitoring within virtual enterprises. Chinese Journal of Management Science, 9(5), 24-31. doi:10.1682/j.cnki.issnl003$207 \times .2001 .05 .004$

Gnyawali, D. R, Park, B. (2009). Co-opetition and technological innovation in small and medium-sized enterprises: a multilevel conceptual model. Journal of small business management, 47(3), 308-330. doi: 10.1111/j.1540-627X.2009.00273.X

Gnyawali, D. R, Park, B. (2011). Co-opetition between giants: collaboration with competitors for technological innovation. Research Policy, 40(5), 650-663. doi: 10.1016/j.respol.2011.01.009

Govindan, K., Chaudhuri, A. (2016). Interrelationships of risks faced by third party logistics service providers: a DEMATEL based approach. Transportation Research Part E: Logistics and Transportation Review, 90(6), 177-195. doi: 10.1016/j.tre.2015.11.010

Gu, X., Cai, C., Song, H., Song, J. (2009). Research on R\&D project risk management model. Communications in Computer and Information Science, 35, 552-558. Doi: 10.1007/978-3-64202298-2_81

Gulati, R. (1995). Does familiarity breed trust? The implications of repeated ties for contractual choice in alliances. Academy of management journal, 38(1), 85-112. doi: 10.5465/256729

Hagedoorn, J. (2002). Inter-firm R\&D partnerships: an overview of major trends and patterns since 1960. Research policy, 31(4), 477-492. doi: 10.1016/S0048-7333(01)00120-2

Heinrich, B., Kundisch, D., Zimmermann, S. (2014). Analyzing cost and risk interaction effects in IT project portfolios. BIT: Banking and Information Technology, 15, 8-20.

Hsu, C., Kuo, T., Chen, S., Hu, A. H. (2013). Using DEMATEL to develop a carbon management model of supplier selection in green supply chain management. Journal of Cleaner Production, 56, 164-172. doi: 10.1016/j.jclepro.2011.09.012

Huang, S. (2010). Research on risk assessment and risk prevention in $R \& D$ alliance. Wuhan University of Technology.

Hwang, W., Hsiao, B., Chen, H., Chern, C. (2016). Multiphase assessment of project risk interdependencies: evidence from a university ISD project in Taiwan. Project Management Journal, 47(1), 59-75. doi: 10.1002/pmj.21563 
Kasap, D., Asyali, I. S., Elci, K. (2007, August 5-9). Risk management in R\&D projects. Portland International Conference on Management of Engineering \& Technology, Portland, USA.

Kwan, T. W., Leung, H. K. N. (2011). A risk management methodology for project risk dependencies. IEEE Trans. on Software Engineering, 37(5), 635-648. doi: 10.1109/TSE.2010.108

Lee, H., Tzeng, G., Yeih, W., Wang, Y., Yang, S. (2013). Revised DEMATEL: resolving the infeasibility of DEMATEL. Applied Mathematical Modelling, 37(10), 6746-6757. doi: 10.1016/j.apm.2013.01.016

Li, Y, Liao, X. (2007). Decision support for risk analysis on dynamic alliance. Decision Support Systems, 42(4), 2043-2059. doi: 10.1016/j.dss.2004.11.008

Liu, R. (2010). Research on risk identification, conduction and evaluation of enterprises' cooperation innovation. Dalian University of Technology.

Liu, S., Zhang, J., Keil, M.,Chen, T. (2010). Comparing senior executive and project manager perceptions of IT project risk: a Chinese Delphi study. Information Systems Journal, 20(4), 319355. doi: 10.1111/j.1365-2575.2009.00333.x

Liu, Y. (2013). Research on the mechanism of corporate risk decision-making of $R \& D$ alliance. Wuhan University of Technology.

Marle, F. (2010, July 22-23). Using DSM approach to manage interactions between project risks. 12th International DSM Conference, Cambridge, UK.

Marle, F., Vidal, L., Bocquet, J. (2013). Interactions-based risk clustering methodologies and algorithms for complex project management. International Journal of Production Economics, 142(2), 225-234. doi: 10.1016/j.ijpe.2010.11.022

Mccutchen, W. W., Swamidass, P. M., Teng B. (2004). R\&D risk-taking in strategic alliances: New explanations for R\&D alliances in the biopharmaceutical industry. Management International Review, 44(1), 53-68.

Opricovic, S., Tzeng, G. (2003). Defuzzification within a multicriteria decision model. International Journal of Uncertainty, Fuzziness and Knowledge-Based Systems, 11(05), 635-652. doi: $10.1142 / \mathrm{S} 0218488503002387$

Parise, S. (2007). Knowledge management and human resource development: An application in social network analysis methods. Advances in Developing Human Resources, 9(3),359-383. doi: 
$10.1177 / 1523422307304106$

Qazi, A., Quigley, J., Dickson A., Kirytopoulos, K. (2016). Project complexity and risk management: towards modelling project complexity driven risk paths in construction projects. International Journal of Project Management, 34(7), 1183-1198. doi: 10.1016/j.ijproman.2016.05.008

Ren, J., Manzardo, A., Toniolo, S., Scipioni, A. (2013). Sustainability of hydrogen supply chain. Part I: identification of critical criteria and cause-effect analysis for enhancing the sustainability using DEMATEL. International Journal of Hydrogen Energy, 38(33), 14159-14171. doi: 10.1016/j.ijhydene.2013.08.126

Ren, S. H., Huang, R. H. (2008). Influencing factor system of intellectual property risk based on cooperative innovation. Science Research Management, 29(2), 75-80. doi: 10.1957/j.cnki.10002995.2008.02.011

Su, S. B., Huang, R. H. (2011). The risk probability measurement-A case study on the trade secret risk caused by the tacit knowledge transferring in collaboration technological innovation. Science Research Management, 32(6), 36-42. doi: 10.19571/j.cnki.1000-2995.2011.06.005

Sun, C. H., Yu, H., Qi, J. G. (2010). Opportunistic behavior of commitment decision in R\&D cooperation. Systems Engineering- Theory \& Practice, 30(3), 447-455.

Tchankova, L. (2002). Risk identification-basic stage in risk management. Environmental Management and Health, 13(3), 290-297.doi: 10.1108/09566160210431088

Teller, J., Kock, A., Gemunden H. G. (2014). Risk management in project portfolios is more than managing project risks: a contingency perspective on risk management. Project Management Journal, 45(4), 67-80. doi: 10.1002/pmj.21431

Vidal, L., Marle, F. (2008). Understanding project complexity: implications on project management. Kybernetes, 37(8), 1094-1110. doi: 10.1108/03684920810884928

Wang, J., Lin, W., Huang ,Y. (2010). A performance-oriented risk management framework for innovative R\&D projects. Technovation, 30(11), 601-611. doi: 10.1016/j.technovation.2010.07.003

Wang, L. (2012). Study of the interconnection between trust, control and risk in $R \& D$ alliance. Southwest University.

Ward, S. (1999). Assessing and managing important risks. International Journal of Project 
Management, 17(6): 331-336. doi: 10.1016/S0263-7863(98)00051-9

Wasserman, S., Faust, K. (1994). Social network analysis: methods and applications. Cambridge University Press.

$\mathrm{Xu}, \mathrm{J}$. (2008). Research on the risk management mechanism of enterprise dynamic alliance. Northeastern University.

Yin, Q., Jia Y. L. (2013). The internal risk management research of industrial technology innovation alliances-based on the analysis of questionnaire survey. Studies in Science of Science, 31(12), 1848-1853. doi: $10.16192 /$ j.cnki.1003-2053.2013.12.013

$\mathrm{Yu}, \mathrm{X}$. D. (2009). The generative mechanism \& evolution of relational risks in cross-board strategic alliances-examples form Zhejiang enterprises. Zhejiang University.

Zhang, S. (2012). Study on risk assessment of organization management in technology research and development alliance. Northeastern University.

Zhang, Y. (2016). Selecting risk response strategies considering project risk interdependence. International Journal of Project Management, 34(5), 819-830. doi: 10.1016/j.ijproman.2016.03.001

Zhang, Y., Yang, N. (2013). Research on robustness of R\&D network under cascading propagation of risk with gray attack information. Reliability Engineering \& System Safety, 117, 1-8. doi: https://doi.org/10.1016/j.ress.2013.03.009

Zhang, Y., Yang, N. (2018). Vulnerability analysis of interdependent R\&D networks under risk cascading propagation. Physica A Statistical Mechanics \& Its Applications, 505, 1056-1068. doi: 10.1016/j.physa.2018.04.063 